Research Article

\title{
Spatial and Temporal Pattern Analysis of Land Use in Yangtze River Delta Based on Remote Sensing and GIS in Intelligent Environment
}

\author{
Hongbing Hu $\mathbb{D}^{1},{ }^{1}$ Linyuan $\mathrm{Wu},{ }^{1}$ Yulan Zhan, ${ }^{2}$ and Shuhui Zhang ${ }^{1}$ \\ ${ }^{1}$ College of Geography and Tourism, Huanggang Normal University, Huanggang 438000, Hubei, China \\ ${ }^{2}$ Library, Huanggang Normal University, Huanggang 438000, Hubei, China \\ Correspondence should be addressed to Hongbing Hu; hihuhb@hgnu.edu.cn
}

Received 13 January 2021; Revised 30 January 2021; Accepted 6 March 2021; Published 16 March 2021

Academic Editor: Sang-Bing Tsai

Copyright (C) 2021 Hongbing Hu et al. This is an open access article distributed under the Creative Commons Attribution License, which permits unrestricted use, distribution, and reproduction in any medium, provided the original work is properly cited.

Land use change plays an important role in regional socio-economic development and global environmental change. Whether the land is effectively and efficiently used is not only related to the income level of the people in the surrounding cities but also closely related to the local economy and national economy. Intelligent environment refers to the indoor environment with a variety of data acquisition equipment. Combined with related technologies, the reasoning and analysis of the data can be used to realize the functions of activity identification, data perception, and control. In addition, the Yangtze River Delta is an economically developed area in China, and its land use situation is related to the economic development in the next ten or even decades. Therefore, it is necessary to analyze the spatial and temporal pattern of land use in Yangtze River Delta region by remote sensing image technology and GIS in intelligent environment. Based on intelligent environment, this paper uses RS and GIS technology to interpret remote sensing image and map land use in multitemporal coastal zone. The land use dynamic degree model and spatial interpolation method were used to analyze and evaluate the spatial and temporal evolution characteristics of land use in the Yangtze River Delta region, and the landscape pattern changes in the Yangtze River Delta region were analyzed and evaluated. This study found that the land use types in the Yangtze River Delta have transformed each other, and the land use change speed is fast, which is inseparable from the rapid economic development. In the future, in addition to maintaining the rapid and stable development of industry, the rational use of limited land resources, the improvement of agricultural development short board, and the improvement of tourism economic benefits will make the economy of the Yangtze River Delta region to a new level.

\section{Introduction}

In recent years, with people's yearning for convenient and comfortable home, office, public service places, and other environment, combined with the support of related technologies, intelligent environment [1] came into being. As the embodiment of the Internet of things technology in the indoor environment, various sensor devices are arranged in the intelligent environment for data acquisition and analysis. Combined with sensor, communication, embedded, automatic control, and other technologies, it can realize the cooperative operation of multiple devices, so as to realize the user's perception and monitoring of data according to different life needs and behavior habits of users, and provide a better environment for users [2]. Land use refers to the long-term or periodic operation and management and transformation of land by human beings according to the natural characteristics of land and according to certain economic and social purposes by adopting a series of biological and technological means. The breadth, depth, and reasonable degree of land use are the concentrated reflection of the scale, level, and characteristics of land production. At present, with the rapid growth of population, the decrease in available land resources, the trend of urbanization, and the increasing expansion of urban area [3] lead to the contradiction between urban land and other sectors of national economy, especially agricultural land. Due to the progress of technology, the ability of human beings to transform and 
utilize the natural environment is increasing day by day. If it is not careful, it will pollute the environment and destroy the ecological balance. In land use, this phenomenon is often more prominent. The status of land use is not only related to the development of local economy and the living conditions of the people but also related to the overall economic development of a country. At present, the situation of land use is mainly affected by man-made destruction, uncontrolled exploitation, and abuse of land. For this, it is very necessary to use science and technology to evaluate the local land condition reasonably and effectively, which can better help the development of local economy and help human beings distribute and utilize the existing land resources more reasonably and effectively.

The Yangtze River Delta is a flat and roughly triangular land formed by the continuous deposition of rivers. The region includes the Jiangsu Zhejiang economic belt with Shanghai as the leader. The Yangtze River Delta cities included Shanghai and 8 cities in the southeast of Jiangsu Province. This area is not only advantageous in geographical location but also rich in talents. Every year, many graduates and social talents come here to seek their ideals and realize their aspirations. In the face of the rapid development of economy and human resources in Japan, the land use situation in this area is also facing huge hidden dangers. Highrise buildings, unreasonable disposal of garbage in scenic spots, and vehicle exhaust pollution are all the land use problems that need to be solved urgently in this area. How to maintain economic development and realize the rational use of land and create available resources for future generations are the urgent problems to be solved.

Remote sensing technology [4] is to detect and identify the electromagnetic wave, visible light, and infrared ray reflected or radiated by the target in a certain distance. All objects have spectral properties, and in particular they have different spectral properties of absorption, reflection, and radiation [5]. Different objects in the same spectrum reflect different spectra. Even the same object, at different times and places, will reflect and absorb different spectra of light due to different angles of sunlight. According to the principle of remote sensing technology, these targets are judged. Remote sensing technology usually adopts green light, red light, and infrared light to detect [6]. The green part is usually used for the detection of groundwater and geotechnical properties. The red part is used to detect plant growth, change, and water pollution. The infrared section detects land, minerals, and resources.

The geographic information system is a rapidly developing spatial information analysis technology. It plays a leading role in the application of resources and environment [7]. Geographic information system technology can not only effectively manage all kinds of resources and environment by using spatial attribute information [8], so that the resource and environment management and practice mode can be analyzed and tested quickly and repeatedly, but also can effectively manage a variety of resources and environments and monitor the changes of resources and environment conditions and production dynamics analysis, and decision-making will also be integrated into a common information stream, which greatly improves work efficiency and economic benefits, solves the problems of resources and environment, and ensures the sustainable development of production. The main application of GIS technology is the management, without data spatial analysis and other decision-making functions. Its application in land science mainly includes land evaluation (land suitability or multiple suitability evaluation, land production potential evaluation, land sustainable use evaluation, urban land price evaluation, and land price evaluation); land use planning (including general plan) and multiobjective land use planning; land use and land cover classification mapping; and dynamic monitoring of the land use cover.

As the most developed area of China's economic development, the Yangtze River Delta region's land use has an important impact on the regional social and economic development. The efficient use of land in this area is not only related to the income level of people in surrounding cities but also closely related to the local economy and national economy and to the economic development in the next decade or even decades. Based on today's intelligent environment, it is necessary to use remote sensing image technology and GIS to analyze the spatial and temporal pattern of land use in the Yangtze River Delta region so as to better help human science control the development of the Yangtze River Delta region. In this paper, remote sensing and geographic information system are used to interpret and map land use in multitemporal coastal zone. Based on the land use dynamic degree model and spatial interpolation method, the spatial and temporal evolution characteristics of land use in the Yangtze River Delta were analyzed and evaluated.

\section{Introduction to Related Theories and Methods}

2.1. Dynamic Degree Model. The dynamic model [9] is a mathematical expression describing the time-varying law between system variables usually expressed by differential equation or difference equation. It is a model that describes system characteristics related to the timing and sequence of operations, events that affect change, sequence of events, context of events, and organization of events. It is usually expressed as a mathematical equation for a continuous or discrete time variable [10]. The dynamic model of the system can be described by sequence diagram, state diagram, and activity diagram.

Using a single land use dynamic degree model, the dynamic change range and rate of various land characteristics in the Yangtze River Delta were studied:

$$
K=\frac{\mathrm{U}_{b}-\mathrm{U}_{a}}{\mathrm{U}_{a}} \times \frac{1}{T} \times 100 \%,
$$

where $K$ is the dynamic degree of a certain land use type in the monitoring period; $U_{a}$ and $U_{b}$ are the areas of the land use type at the beginning and the end of the study; and $T$ is the monitoring period. 
The comprehensive land use dynamic degree model is used to characterize the spatial change characteristics and transfer speed of land use:

$$
\mathrm{LC}=\frac{\sum_{i=1}^{n} \mathrm{LU}_{i-j}}{2 \sum_{i=1}^{n} \mathrm{LU}_{i}} \times \frac{1}{T} \times 100 \% .
$$

In the formula, $\mathrm{LC}$ is the comprehensive dynamic degree of land use in the study area and $\triangle \mathrm{LU}_{i-j}$ is the conversion of type I land use type to non-I type, $J$ type, $J=1,2,3 \ldots, n$ is the area of the first type of land use type at the initial stage of monitoring; $n$ is the total number of land use types; and $T$ is the monitoring interval [11].

2.2. Space Insertion Value. The space insertion value method [12] is usually used to transform the measured data of discrete points into continuous data surfaces and compare them with the distribution patterns of other spatial phenomena. The spatial interpolation algorithm is defined that derived from the data of known points in the same region unknown point data. Spatial extrapolation is defined that the extrapolation of data from a known region to another region. There are two spatial interpolation methods, the first one is deterministic method and the second one is geostatistical method. Deterministic interpolation is a method of establishing installation surfaces, such as inverse distance weighted average interpolation, spline function, and other geostatistical interpolation methods, such as using the statistical regularity of sampling points to quantify the spatial autocorrelation relationship between sampling points. This interpolation method is used to establish the model points of the surrounding prediction sample spatial structure. points of the spatial structure of the surrounding prediction samples. The characteristic of the deterministic interpolation method is that the interpolation result of the sampling point is basically consistent with the actual value of the original sampling point. If the uncertain interpolation method is used, the interpolation results of the sampling points are not necessarily consistent with the measured values of the samples, and some of them are far away from each other.

In order to analyze the hot spots of the use of land change, the study area was divided into grid. The spatial interpolation method considers that the points with close spatial distribution have similar eigenvalues. The spatial interpolation can calculate the data of other unknown points in the research area through the center of gravity data of known grid and simulate the discrete gravity center calculation data as continuous data surface, which is convenient for the comparison of spatial distribution models.

2.3. Landscape Pattern Analysis. Landscape pattern [13] basically means the spatial arrangement and combination of landscape elements of different sizes and shapes. For example, different types of patches can be randomly distributed, evenly distributed, or aggregated in space. The spatial distribution of landscape elements is regular and forms various patterns. Landscape elements are called configuration (configuration). From the perspective of spatial distribution of landscape elements, there are five most obvious configurations, which are uniform distribution pattern, agglomeration distribution mode, linear distribution mode, parallel distribution mode, and specific combination or spatial connection.

Landscape stability can be analyzed and evaluated by landscape pattern, that is, landscape spatial structure characteristics, and characterized by landscape index changes. The calculation of landscape index is based on FRAGSTATS software platform and based on the spatial distribution map from 2015 to 2019.

Landscape stability is maintained by the spatial heterogeneity [14] of landscape pattern, which is the basis of ecological service function. Due to the correlation of some indexes in the landscape index, in order to avoid the cumbersome analysis and better global analysis, combined with the characteristics, the number of patches, Shannon diversity index, Shannon evenness index, perimeter area ratio fractal dimension, landscape condensation index, dispersion, and juxtaposition index were selected to calculate the year 2015 and 2016. The landscape index data of Yangtze River Delta in 2017, 2018, and 2019 are used to describe the patch characteristics, dispersion and adjacency characteristics, diversity characteristics, and fragmentation information of the Yangtze River Delta landscape.

\section{Experimental Process of Spatial and Temporal Pattern Analysis of Land Use}

3.1. Remote Sensing Image Classification Processing. The accuracy evaluation is a crucial step in land use remote sensing monitoring [15] and also a measure of whether the classification results are credible. In general, sampling inspection should be carried out for accuracy evaluation. The sampling methods generally include systematic sampling, random sampling, zonal sampling, systematic sampling, and partitioned random sampling. Shi Peijun then conducted field investigation or used more accurate data such as largescale aerial photos to obtain verification data and established error matrix on this basis to calculate various precision indexes. Accuracy evaluation based on pixel level is a common method. The calculation of pixel level classification accuracy is based on error matrix. Each row of the error matrix represents the distribution of sampling points of a certain type of land use type in the actual verification data of remote sensing classification images, and the diagonal part represents the number of sample points of a certain type consistent with the verification data.

3.2. Land Use Pattern at Landscape Scale. In order to study the degree of fragmentation of the landscape, the number of patches is selected as the analysis index, which represents the total number of patches. The higher the value, the higher the degree of fragmentation of the landscape [16]. A patch is a landscape pattern different from a relatively uniform nonlinear area. Fragment is common in all hierarchical systems in nature, and it reflects internal and internal similarity or difference systems. Different patch sizes, shapes, boundary 
properties, distances, and other spatial distribution characteristics constitute different ecological zones, forming ecological differences and regulating ecological processes.

Fractal dimension [17] is a concept of dimension proposed by mathematicians from the perspective of measurement in 1919. In order to quantitatively describe the "irregular" degree of objective things, the fractal dimension is extended from integer to fraction, which breaks the boundary that the dimension of general topological set is integer. Resolution is also called resolution. In order to judge the separation degree of the separated substance on the chromatographic column, the resolution is usually used as the total separation efficiency index of the column. $R$ is the ratio of the retention time difference of adjacent chromatographic peaks to the average peak width of two chromatographic peaks, indicating the separation degree of adjacent chromatographic peaks. The greater $R$, the better the separation of adjacent components.

Dominance is used to represent the status and role of a group. Ecological dominance index [18] reflects the change of species populations. The more uneven the distribution of the species population, the more obvious its ecological advantages. Uniformity represents the distribution of the total number of species in a community or habitat and reflects the uniformity of species distribution. In any environment, there is diversity. On the macrolevel, ecological environment and social culture will present diversity. Intuitively, it is the diversity of biological species and commercial products. At the microscopic level, the genetic diversity of the same species is also diverse. There is often a dynamic balance between different levels of diversity, some of which have been eliminated and new forms have emerged that are different from the past. Diversity has always existed in the ecological aspects, such as biological diversity, species diversity, ecosystem diversity, cultural diversity, genetic diversity, and so on.

3.3. Measurement of Average Dimension of Land Patches. Landscape pattern index [19] refers to landscape pattern and landscape index. Usually it refers to the landscape structure in the landscape spatial structure, which is formed by nature or man-made. A series of landscape mosaics with different shapes, sizes, and arrangements are arranged in the landscape space. It is the performance of landscape heterogeneity and various ecological processes at different scales, including the interference effect on the results. Spatial patch is the most common form of landscape pattern, which is shown in different scales. Landscape pattern [20] and its changes are the result of the interaction of natural and human factors and must be the comprehensive reflection of the regional ecological environment system. The type of landscape patches is the result of the interaction of various interference factors and affects the development of the regional ecological environment system, regional ecological process, and edge effect [21].

3.4. Cohesion Calculation and Analysis of Landscape Condensation Index. In the analysis of land use in this area, the national policy, economic policy, and population policy are also inseparable. National policies and land planning affect the scale, speed, and direction of regional construction, as well as the transfer direction of land use [22]. National policies can be reflected by the fixed investment of the whole society. The fixed investment amount of the whole society can be divided into capital construction, real estate development, urban and rural reconstruction, and other investment, which can reflect the national policy tendency. The GDP index can best measure the regional economic development. There is an obvious positive correlation between construction land and GDP in the Yangtze River Delta, which shows that construction land will increase with GDP growth. Therefore, GDP is an important driving factor for the evolution of spatial pattern [23]. At the same time, the proportion of the tertiary industry and tourism is gradually increased, which promoted the population movement [24], driving the development of the local economy. The increase in population will directly lead to urban and rural expansion, resulting in the increase in construction land and road construction demand, thus accelerating the development of urbanization [25]. This will inevitably lead to the expansion of construction land area, increase the employment demand, and gradually increase the number of employees. Population growth promotes the development of urbanization. In order to disperse the pressure of population living and employment, the scale of construction land and road construction is expanding.

\section{Result Analysis}

4.1. Accuracy Evaluation of Remote Sensing Image Classification. As shown in Table 1, the total accuracy of supervised classification of remote sensing images in 2015 was $92.10 \%$, which exceeded $80 \%$ in terms of producer accuracy. From the perspective of user accuracy, the classification accuracy of all categories exceeded $75 \%$, and the index was 0.92 , indicating that some points in the classification process were given correct categories.

As shown in Table 2, the total accuracy of remote sensing image supervised classification in 2019 is $91.13 \%$. From the perspective of producer accuracy, the accuracy of all categories exceeds $80 \%$ and that of all user categories exceeds $75 \%$. The index is 0.88 , which indicates that some points of remote sensing images in the classification process have been assigned the correct classification.

4.2. Analysis of Land Use Pattern Change on Landscape Scale. As shown in Figure 1, the total number of patches of land use types in the Yangtze River Delta region under the intelligent environment is on the rise over time. From 15000 in 2015 to 18000 in 2016, an increase of 3000 is observed, and then from 18000 in 2016 to 19320 in 2017, an increase of 1320 is observed, and then from 19320 in 2017 to 20000 in 2018, an increase of 680 is observed, and then from 20000 in 2018 to 21002 in 2019, an increase of 1002 is observed.

4.3. Comparison of Average Dimensions of Land Patches. In the intelligent environment, the patch density of land use types also shows the same upward trend as the number of 
TABLE 1: Error matrix of TM image surveillance classification in 2015.

\begin{tabular}{|c|c|c|c|c|c|c|c|c|c|c|c|}
\hline Data & 1 & 2 & 3 & 4 & 5 & 6 & 7 & 8 & 9 & Line total & User accuracy \\
\hline 1 & 18 & 0 & 0 & 0 & 0 & 0 & 0 & 0 & 0 & 18 & 100 \\
\hline 2 & 0 & 35 & 5 & 0 & 0 & 0 & 0 & 0 & 0 & 40 & 93.40 \\
\hline 3 & 0 & 4 & 12 & 0 & 0 & 0 & 0 & 0 & 0 & 16 & 84.43 \\
\hline 4 & 0 & 0 & 0 & 67 & 0 & 0 & 0 & 0 & 3 & 70 & 94.32 \\
\hline 5 & 0 & 0 & 0 & 0 & 123 & 6 & 0 & 0 & 0 & 129 & 95.25 \\
\hline 6 & 0 & 0 & 0 & 0 & 5 & 46 & 0 & 0 & 0 & 51 & 87.14 \\
\hline 7 & 0 & 0 & 0 & 0 & 0 & 0 & 12 & 2 & 0 & 14 & 91.10 \\
\hline 8 & 0 & 0 & 0 & 0 & 0 & 0 & 2 & 6 & 0 & 8 & 89.90 \\
\hline 9 & 0 & 0 & 0 & 8 & 0 & 0 & 0 & 0 & 35 & 43 & 83.04 \\
\hline Column total & 18 & 39 & 17 & 75 & 128 & 52 & 14 & 8 & 38 & & \\
\hline Producer's accuracy & 100 & 95.46 & 78.78 & 87.65 & 95.68 & 85.54 & 92.13 & 88.82 & 87.78 & & Kappa index $=0.92$ \\
\hline
\end{tabular}

Index note: 1 represents water area, 2 represents residential area, 3 represents industrial and mining land, 4 represents bare land, 5 represents plain desert grassland, 6 represents mountain desert grassland, 7 represents cultivated land, 8 represents woodland, and 9 represents surrounding land.

TABLE 2: Error matrix of TM image surveillance classification in 2019.

\begin{tabular}{|c|c|c|c|c|c|c|c|c|c|c|c|}
\hline Data & 1 & 2 & 3 & 4 & 5 & 6 & 7 & 8 & 9 & Line total & User accuracy \\
\hline 1 & 16 & 0 & 0 & 0 & 0 & 0 & 0 & 0 & 0 & 16 & 100 \\
\hline 2 & 0 & 30 & 3 & 1 & 0 & 3 & 0 & 0 & 0 & 36 & 94.40 \\
\hline 3 & 0 & 3 & 12 & 0 & 0 & 0 & 0 & 0 & 0 & 15 & 86.43 \\
\hline 4 & 0 & 0 & 0 & 46 & 2 & 3 & 0 & 1 & 3 & 55 & 78.32 \\
\hline 5 & 0 & 2 & 0 & 0 & 74 & 2 & 0 & 0 & 0 & 78 & 89.25 \\
\hline 6 & 0 & 1 & 1 & 0 & 5 & 87 & 0 & 0 & 0 & 94 & 97.14 \\
\hline 7 & 0 & 0 & 0 & 0 & 0 & 1 & 12 & 2 & 0 & 15 & 90.10 \\
\hline 8 & 0 & 0 & 0 & 0 & 0 & 2 & 2 & 6 & 0 & 10 & 88.90 \\
\hline 9 & 0 & 1 & 0 & 4 & 0 & 0 & 0 & 0 & 35 & 40 & 84.04 \\
\hline Column total & 16 & 37 & 16 & 51 & 81 & 102 & 14 & 9 & 38 & & \\
\hline Producer's accuracy & 100 & 87.46 & 81.20 & 87.65 & 94.68 & 86.54 & 92.13 & 89.82 & 87.78 & & Kappa index $=0.88$ \\
\hline
\end{tabular}

Note: 1 represents water area, 2 represents residential area, 3 represents industrial and mining land, 4 represents bare land, 5 represents plain desert grassland, 6 represents mountain desert grassland, 7 represents cultivated land, 8 represents woodland, and 9 represents surrounding land of buildings.

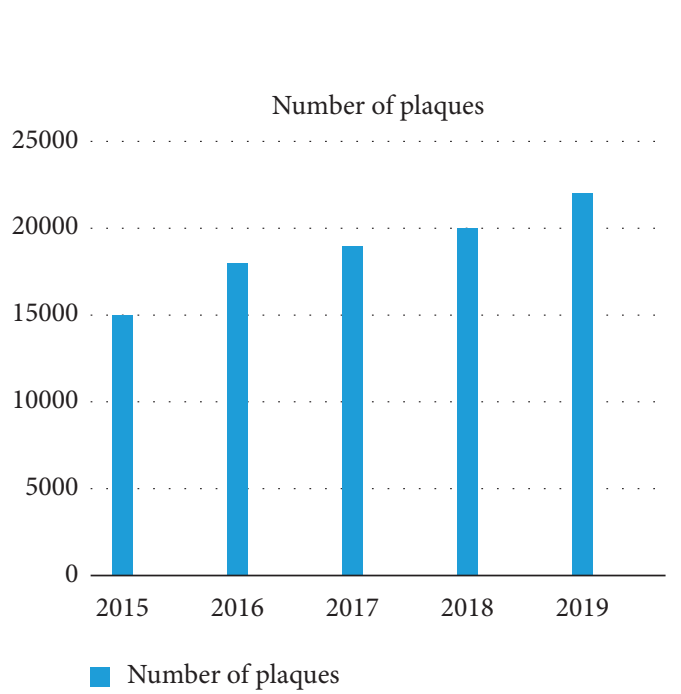

(a)

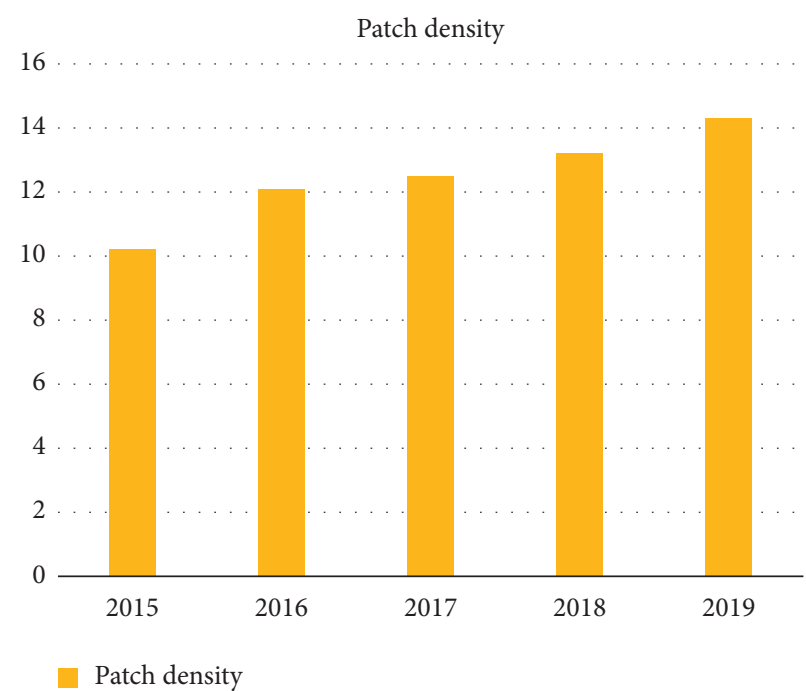

(b)

Figure 1: Number and density of landscape patches in Yangtze River Delta from 2015 to 2019.

patches, from 10.5 in 2015 to 12.2 in 2016, from 12.2 in 2016 to 12.7 in 2017 , from 12.7 in 2017 to 13.4 in 2018 , and then from 13.4 in 2018 to 14.6 in 2019 , showing an upward trend.

As shown in Figure 2, based on the intelligent environment, the average fractal dimension of land use patches in Yangtze River Delta changed greatly in 2016. The average fractal dimension of the whole patch showed a downward trend: 028 in 2015, 1.003 in 2016, 0.996 in 2017, 0.985 in 2018 , and 0.974 in 2019 . The average fractal dimension index means the degree of self-similarity of patches, which reflects 


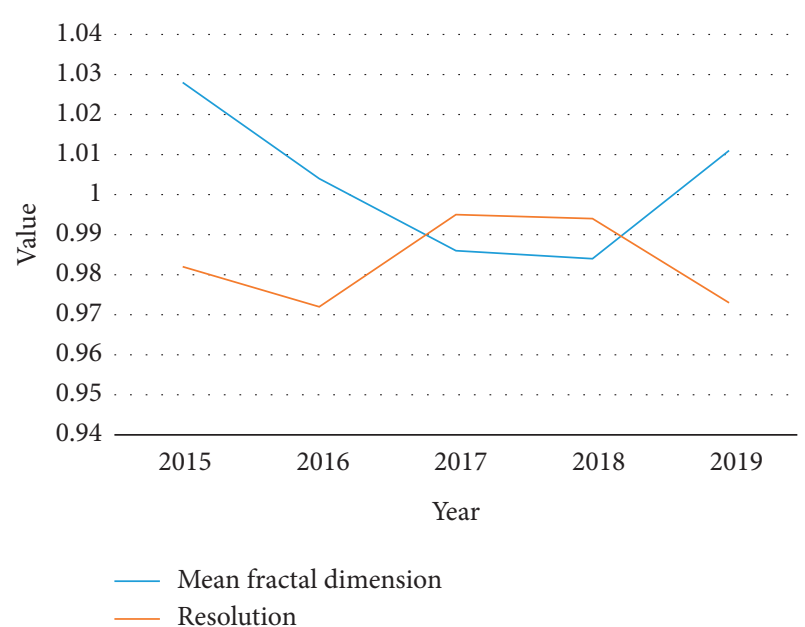

FIgURE 2: Average fractal dimension and separation degree of landscape types in Yangtze River Delta from 2015 to 2019.

the impact of human activities on patches to a certain extent. Landscape separation refers to the degree of spatial distribution of landscape types. This shows that the patch shape of each landscape type is complex and relatively concentrated during the year. Under the interference of human activities, the shape of each landscape type is regular and widely distributed. However, except for the decrease in 2016, the degree of separation showed an upward trend in other years. Under the interference of human activities, the morphology of each landscape type has a certain regularity and wide distribution. It was 982 in 2015, decreased to 0.972 in 2016, increased to 0.986 in 2017, continued to rise to 0.994 in 2018 , and continued to rise to 1.012 in 2019 .

As shown in Figure 3, the landscape diversity of Yangtze River Delta based on intelligent environment is increasing year by year, from 1.8 in 2015 to 1.97 in 2016, to 2.02 in 2017, to 2.34 in 2018 , and to 2.56 in 2019 . This shows that the region in the economic development at the same time and the same attention to landscape development pays attention to the tourism industry. In addition, the overall landscape dominance of the Yangtze River Delta region is also increasing year by year, from 0.34 in 2015 to 0.47 in 2016, to 0.50 in 2017, to 0.69 in 2018, and to 0.72 in 2019. This shows that the landscape advantage of this area is gradually highlighted, and the degree of people's care for the landscape is illustrated. In addition, the overall landscape evenness of the Yangtze River Delta is also increasing year by year, from 0.7 in 2015 to 0.8 in 2016, 0.9 in 2017, 1.0 in 2018, and 1.3 in 2019. The results show that the area proportion difference of various landscape components is gradually narrowing, the distribution of each component in the landscape is more and more uniform, and the dominance of one or several landscape components is less and less, and the overall structure of landscape is greatly affected by human activities.

4.4. Landscape Condensation Index. As shown in Figure 4, in the intelligent environment, the spatial connectivity of landscape types is characterized, and the cohesion index of landscape is selected to calculate and analyze. When the value

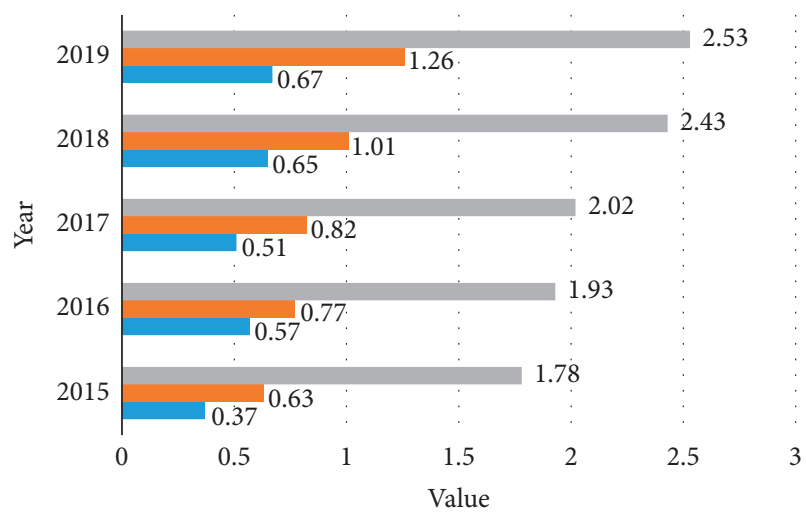

$$
\begin{aligned}
& \text { - Diversity } \\
& \text { - Uniformity } \\
& \text { - Dominance }
\end{aligned}
$$

Figure 3: Overall landscape diversity index from 2015 to 2019.

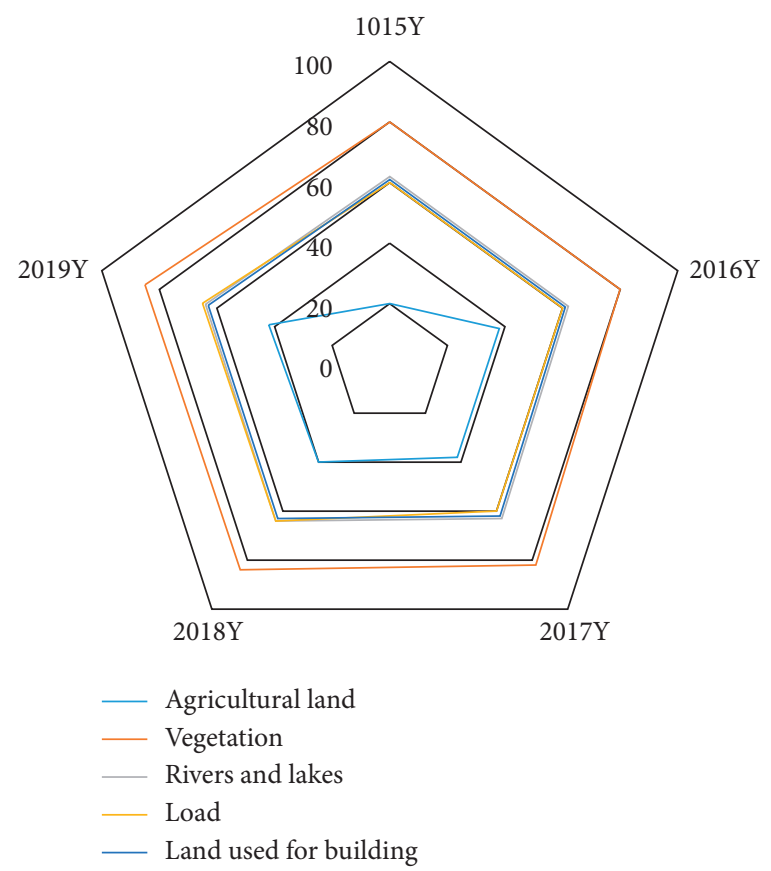

FIgURE 4: Spatial connectivity of landscape types in Yangtze River Delta.

of cohesion is large, the connectivity is good, and the smaller the value, the worse the connectivity. Under the intelligent environment, the development and change of road connectivity are the biggest; because of the rapid economic development in the Yangtze River Delta region and the continuous construction of high-speed rail and maglev trains, the road connectivity in the region has become more connected. The connectivity of intelligent construction land is increasing year by year, which shows that the economic development of the region promotes the construction of high-rise buildings, and there was continuous land construction into high-rise buildings. The rivers and lakes in this area are basically stable, indicating that the ecological protection of rivers and lakes is better. At the same time, the vegetation condition in this area 
is developing well, which indicates that the region should pay attention to the protection of ecological environment and the planting of green vegetation in response to the call of the times. However, in recent years, the amount of agricultural connectivity has gradually increased. In the intelligent environment, we want to balance the coordinated and stable development of agriculture and industry.

\section{Conclusions}

Intelligent environment involves a wide range of technologies and has a large number of cross applications with other fields. The related technologies supporting intelligent environment are becoming more and more powerful. This chapter mainly uses the relevant land use analysis methods and qualitative analysis to study the transformation and change of land use types in the Yangtze River Delta region. In different periods, both the overall landscape characteristics and the spatial characteristics of various landscape types in Wuhai City have obvious changes. The characteristics are as follows: the landscape heterogeneity is improved, the proportion of vegetation, river, and lake water land is increasing, and the proportion of different land use types in the whole region is gradually narrowing. With the rapid development of industry, the scale has been regulated, the industrial and mining location is relatively scattered, and the environment has been improved. With the development of economy in the Yangtze River Delta, the area of surrounding buildings tends to decrease and the problem of land degradation has been improved. The implementation of the water allocation quota system of agricultural and forestry land also reflects the unified planning of agricultural and forestry land, the improvement of environmental protection awareness, and the improvement of various measures. The range of land use has changed greatly, and the types of land use have transformed each other, and the speed of land use change is fast, which is inseparable from the rapid economic development; the distribution of land use pattern is more and more uniform, the area difference between patches is gradually narrowing, and the dominance of a certain land use type is gradually reduced. During the study period, the pattern of land use in the Yangtze River Delta has changed greatly. At the same time of economic development, the impact of human on land use change is dramatic, which can further affect the ecological function of the whole Yangtze River Delta.

The change of spatial and temporal pattern of land use can lead to the change of environmental ecological function. The application of remote sensing and geographic information system in the intelligent environment is the mainstream method of land use analysis. In this study, remote sensing image is used as the data source of land use analysis and the geographic information system is used as the platform for analyzing and processing the data, so as to find out the relationship between land use type and vegetation cover, which can lay a foundation for future research on land type change in the same area. And it has important guiding significance for the further study of land use in Yangtze River Delta.

\section{Data Availability}

No data were used to support this study.

\section{Conflicts of Interest}

The authors declare that they have no conflicts of interest.

\section{Acknowledgments}

This work was supported by the College Students Innovation and Entrepreneurship Training Program (nos. S201910514006 and 202010514014).

\section{References}

[1] L. H. Trinh, T. G. Le, V. H. Kieu, T. M. L. Tran, and T. T. N. Nguyen, "Application of remote sensing technique for shoreline change detection in ninh binh and nam dinh provinces (Vietnam) during the period 1988 to 2018 based on water indices," Russian Journal of Earth Sciences, vol. 20, no. 2, pp. 1-15, 2020.

[2] M. Elhoseny, "Multi-object detection and tracking (MODT) machine learning model for real-time video surveillance systems," Circuits, Systems, and Signal Processing, vol. 39, pp. 611-630, 2019.

[3] M. Saracevic, S. Adamović, N. Macek, M. Elhoseny, and S. Sarhan, "Cryptographic keys exchange model for smart city applications," IET Intelligent Transport Systems, vol. 14, no. 5, 2020, In press.

[4] J. Liu, Y. Liu, and X. Wang, "An environmental assessment model of construction and demolition waste based on system dynamics: a case study in Guangzhou," Environmental Science and Pollution Research, vol. 27, no. 30, pp. 37237-37259, 2019.

[5] B. Zhu, S. Ma, R. Xie, J. Chevallier, and Y.-M. Wei, "Hilbert spectra and empirical mode decomposition: a multiscale event analysis method to detect the impact of economic crises on the European carbon market," Computational Economics, vol. 52, no. 1, pp. 105-121, 2018.

[6] C. Han, B. Zhang, H. Chen, Z. Wei, and Y. Liu, "Spatially distributed crop model based on remote sensing," Agricultural Water Management, vol. 218, pp. 165-173, 2019.

[7] Z. Lv, X. Li, and W. Li, "Virtual reality geographical interactive scene semantics research for immersive geography learning," Neurocomputing, vol. 254, pp. 71-78, 2017.

[8] G. Ljubomir, P. Dragan, B. Zoran, and D. Siniša, "Application of GIS-interval rough AHP methodology for flood hazard mapping in urban areas," Water, vol. 9, no. 6, pp. 1-26, 2017.

[9] Z. Shao, H. Sun, X. Wang, and Z. Sun, "An optimization mining algorithm for analyzing students' learning degree based on dynamic data," IEEE Access, vol. 8, pp. 113543113556, 2020.

[10] E. Laxmi Lydia, J. Samuel Raj, R. Pandi Selvam, M. Elhoseny, and K. Shankar, "Application of discrete transforms with selective coefficients for blind image watermarking," Transactions on Emerging Telecommunications Technologies, vol. 32, no. 2, 2019, In press.

[11] L. H. Son, F. Chiclana, R. Kumar et al., "Arm-amo: an efficient association rule mining algorithm based on animal migration optimization," Knowledge-Based Systems, vol. 154, pp. 68-80, 2018.

[12] L. Tan, G. Wan, F. Li, X. Chen, and W. Du, "GPU based contouring method on grid dem data," Computers \& Geosciences, vol. 105, pp. 129-138, 2017. 
[13] S. Shimizu, P. Stradins, M. Kondo, and A. Matsuda, "Investigation of light-induced defect depth profile in hydrogenated amorphous silicon films," Japanese Journal of Applied Physics, vol. 41, no. 11B, pp. L1297-L1299, 2018.

[14] P. Xu, H. Huang, N. Dong, and S. C. Wong, "Revisiting crash spatial heterogeneity: a Bayesian spatially varying coefficients approach," Accident Analysis \& Prevention, vol. 98, pp. 330337, 2017.

[15] Q. Kuang, Q.-Z. Yuan, J.-C. Han et al., "A remote sensing monitoring method for alpine grasslands desertification in the eastern Qinghai-Tibetan plateau," Journal of Mountain Science, vol. 17, no. 6, pp. 1423-1437, 2020.

[16] C. Rodríguez Fernández-Blanco, S. L. Burns, and L. Giessen, "Mapping the fragmentation of the international forest regime complex: institutional elements, conflicts and synergies," International Environmental Agreements: Politics, Law and Economics, vol. 19, no. 4, pp. 187-205, 2019.

[17] A. D. Chan, D. Grynspan, and R. P. Jankov, "Fractal dimension does not correlate as well with models of neonatal chronic lung injury as it does with placental distal villous hypoplasia," Pediatric and Developmental Pathology, vol. 22, no. 2, pp. 171-174, 2019.

[18] J. Tang, Z. Chen, and J. Fang, "Application of ecological footprint," Asian Agricultural Research, vol. 9, no. 3, pp. 57-60, 2017.

[19] P. Szilassi, T. Bata, S. Szabó, B. Czúcz, Z. Molnár, and G. Mezősi, "The link between landscape pattern and vegetation naturalness on a regional scale," Ecological Indicators, vol. 81, pp. 252-259, 2017.

[20] L. Zhang, G. Jin, X. Wei, P. Xie, G. Liu, and Y. Liu, "Multiscale analysis of patch and landscape characteristics of forest fragmentation in Liaoning province, China," Regional Environmental Change, vol. 19, no. 4, pp. 1175-1186, 2019.

[21] R. Wu, M. J. Heng, G. Q. Zha, and W. Q. Jie, “The mechanism of edge effect in Cdznte Pixel detector and an improved design of pixel sizes of anode," Journal of Instrumentation, vol. 15, no. 4, Article ID C04043, 2020.

[22] T. Kizu, Z. Wang, and E. E. Manrique, "Labour flexibility, capital structure and enterprise performance," World Employment and Social Outlook, vol. 2017, no. 3, pp. 41-72, 2017.

[23] L. Zhou, C. Zhou, L. Che, and B. Wang, "Spatio-temporal evolution and influencing factors of urban green development efficiency in China," Journal of Geographical Sciences, vol. 30, no. 5, pp. 724-742, 2020.

[24] F. V. Sleznov, "Experience in the development of administrative functions in the suburban areas of large agglomerations," Regional Research of Russia, vol. 10, no. 1, pp. 97-106, 2020.

[25] P. Collier, "African urbanization: an analytic policy guide," Oxford Review of Economic Policy, vol. 33, no. 3, pp. 405-437, 2017. 